\title{
Periodismo, negocios y política durante el tercer peronismo: la revista Panorama (1973-1975)
}

\author{
Journalism, business and politics during the third Peronism: the \\ Panorama magazine (1973-1975)
}

\author{
Patricia Alejandra Orbe patriciaorbe@gmail.com \\ Universidad Nacional del Sur/ \\ Consejo Nacional de Investigaciones Científicas y Técnicas (Argentina)
}

María Celeste Napal celestenapal@hotmail.com

Universidad Nacional del Sur (Argentina)

\section{Resumen}

El estudio de la prensa durante el tercer gobierno peronista es un campo que merece ser investigado con mayor profundidad. Con el objetivo de realizar un aporte en este sentido, nos proponemos analizar el discurso periodístico de la revista Panorama, editada por la Editorial Abril. Para ello nos centraremos en las representaciones que esta publicación de actualidad 
producía en relación al peronismo y sus principales representantes, al tiempo que su empresa editora atravesaba una grave crisis por efecto de las presiones políticas y económicas que recibía desde sectores ligados al oficialismo, circunstancia que conduciría al cierre de la revista y al ocaso de su trayectoria institucional.

Palabras clave: peronismo; revista Panorama; Editorial Abril; papel prensa.

\begin{abstract}
The study of the press during the third peronist government is a field that currently deserves to be investigated in greater depth. With the aim of making a contribution in this regard, we propose to take as an object of analysis the journalistic discourse of Panorama magazine of Abril, a renowned editorial publishing house. For such purpose, we will focus on the representations that this magazine published about peronism and its main representatives, while its publishing company was going through a serious crisis due to the political and economic pressures it received from sectors linked to the ruling party, a circumstance that would lead to the closing of the magazine and the decline of its institutional trajectory.
\end{abstract}

Keywords: Peronism; Panorama magazine; Abril publishing house; newsprint paper.

En los últimos años, se han realizado notables avances dentro del campo del conocimiento del acontecer nacional durante la primera mitad de la década del setenta, signada por el retorno del peronismo al gobierno (Lida, Crespo y Yankelevich, 2007; Franco, 2012; Vezzetti, 2013; Águila, Garano y Scatizza, 2016). En ciertos casos, los aportes se han centrado específicamente en el análisis de diversas publicaciones periódicas de la época (Díaz, Giménez y Passaro, 2001; Borrelli, 2015), poniendo en evidencia la riqueza de la etapa en materia de experiencias editoriales centradas en revistas de índole diversa, las cuales se desplegaban desde el campo del periodismo de extracción militante (Peller, 2007; Cucchetti, 2008; Besoky, 2010; Bufano y Lotersztain, 2010; Nadra y Nadra, 2011; Slipak, 2015; Grassi, 2015) y político-cultural o intelectual (Rodríguez Agüero, 2007; Sonderéguer, 2008; Pozzoni, 2012; Tortti, 2014), al del nacionalismo (Orbe, 2012a y 2012b) y el catolicismo (Borrelli, 2011b; Rodríguez, 2012), entre otros. En este contexto, recientemente han emergido iniciativas que toman a las revistas de actualidad o magacines como objeto de estudio durante el tercer gobierno peronista dado que no han recibido la misma atención por parte de los investigadores 
a pesar de su preeminencia en materia de tirada y penetración en la opinión pública. En nuestro caso, nos hemos detenido en el abordaje del discurso periodístico de Panorama, una de las publicaciones más exitosas de la editorial Abril, que había salido al mercado en 1963. Si bien Panorama ha recibido un tratamiento general en investigaciones abocadas a la reconstrucción de la trayectoria institucional de la editorial Abril (Scarzanella, 2016) y ha sido tomada como fuente documental en estudios sobre las transformaciones socioculturales de los años 60 y 70 (Cosse, 2013; Manzano, 2017), consideramos que merece ser revisitada con mayor detenimiento y profundidad (1) en virtud de la relevancia de su éxito editorial por aquellos años y por tratarse de la principal publicación de una empresa que se vio involucrada en una serie de conflictos político-económicos con insignes funcionarios del oficialismo, los cuales derivarían en el ocaso de la revista y de su firma responsable.

En esta oportunidad, nos proponemos analizar el discurso de Panorama en torno a las representaciones que difundía en relación al peronismo y sus principales referentes, atendiendo especialmente a inserción de dicho discurso en el marco de la crisis que atravesaba la editorial Abril por las presiones, amenazas y atentados contra sus integrantes perpetrados desde las esferas estatales y que desembocarían en el desmembramiento de la empresa y cierre de la revista. A tal efecto, a continuación nos introduciremos en los principales aspectos del itinerario de la editorial Abril y los rasgos distintivos de Panorama como publicación de actualidad.

\section{Abril: un "botín de guerra"}

Editorial Abril fue fundada el 21 de noviembre de 1941 y constituida como sociedad anónima comercial e industrial el 24 de junio de 1953, iniciativa en la cual participaban como accionistas distintos inmigrantes italianos -como Cesare Civita, su presidente- que habían abandonado la península ante la amenaza que constituían las leyes antisemitas aplicadas a fines de los años 30 (Scarzanella, 2016: 18-27). Durante sus primeros pasos, la editorial realizó publicaciones infantiles con gran éxito, lanzó "novelas semanales", series de grandes clásicos de la literatura para adultos y colecciones de obras destacadas en las Ciencias Sociales, a bajo costo, dirigidas a un público popular.

Mientras Abril ascendía por la escalera del prestigio editorial y se consolidaba a nivel comercial, comenzaba a participar del convulsionado clima político de la época. Los antifascistas italianos ligados a la empresa se alinearon con la Unión Democrática en contra de la candidatura de Juan Domingo Perón, con lo que dieron comienzo a la sinuosa relación que habría de 
mantener Abril con el peronismo. Entre 1946 y 1955, los dueños de la editorial debieron hacer concesiones ante las presiones estatales para con los empresarios extranjeros: se vieron obligados a naturalizarse y el hecho de dar "refugio" a intelectuales de izquierda- como Boris Spivacow, Oscar Varsavsky y Cora Ratto- que habían sido marginados de sus cátedras por sus simpatías políticas, les ganó el calificativo de "simpatizantes comunistas", atribuido por el servicio de inteligencia del Ejército.

Más allá de estas dificultades políticas, la editorial crecía. El aumento de lectores estimulaba el crecimiento del volumen de avisos publicitarios. Por otro lado, Abril aumentó su capacidad de distribución absorbiendo a su revendedor utilizado hasta ese momento y creó su propia sociedad -Ryela (Revistas y Ediciones Latino Americanas)- y más tarde su propia agencia de publicidad. El éxito editorial de Abril llevó a Civita a dirigir la Asociación Argentina de Editores de Revistas (AAER), organismo que se encargaba de las relaciones del sector con las autoridades, los revendedores y los sindicatos (Scarzanella, 2016: 113).

Fiel a su costumbre de ofrecer al público productos novedosos, en 1957, la editorial lanzó al mercado la revista femenina Claudia, la cual se transformó inmediatamente en un éxito (Cosse, 2013). Entre 1966 y 1968, editó la revista Adán, entretenimiento para gentilhombres, publicación que abordaba temas eróticos con sobriedad, junto a cuestiones de la economía, la cultura, la ciencia y el tiempo libre tratando de captar la atención de los jóvenes ejecutivos en ascenso (Giordano, 2014). Por otra parte, inauguró Parabrisas -luego rebautizada como Corsa en 1966-, una revista dedicada predominantemente al automovilismo, que se sumaba a las revistas Panorama (1963), Siete Días llustrados (1967) y Semana Gráfica (1969), todas ellas publicaciones de actualidad incorporaban información de escala mundial gracias a las licencias de editores norteamericanos y europeos.

También fueron años del comienzo de un proceso de integración vertical con la creación de un establecimiento gráfico en 1963. La sociedad Fabril Financiera había impreso hasta el momento las revistas de la editorial y al asociarse a ella, Abril pudo usufructuar las estrechas relaciones de aquella con el poder político y militar.

Luego del golpe de estado de 1966 y ante la iniciativa dictatorial de estudiar la factibilidad técnico-económica para la producción nacional de papel, el presidente de Abril motorizaría la creación de la sociedad Promotora Industrial del Papel (Proinpa), la cual se constituyó el 3 de abril de 1968 con sede legal en la misma dirección de la editorial.

Durante la presidencia de Alejandro Lanusse, finalmente Civita obtuvo la autorización del gobierno para hacer una fábrica de papel de diarios y se constituyó una sociedad mixta con el Estado para la producción local de este insumo. La sociedad Proinpa se convirtió en Papel Prensa S. A. en octubre de 1972 (Borrelli, 2011a: 30), y entre sus socios se contaban Cesare 
Civita, César Alberto Doretti -de Fabril Financiera y Celulosa- y Luis Rey -presidente de la sociedad Tauro, la cual construiría la fábrica con financiación del Banco Nacional de Desarrollo-.

En este proyecto se encontraba inmersa la empresa al momento del retorno del peronismo al gobierno. El grupo Abril seguía despertando desconfianza y malestar en Perón, pero otros intereses económicos y políticos intervinieron para convertir a la empresa de Civita en un "botín de guerra" que la llevaría a la declinación y el ocaso (Scarzanella, 2016: 181).

Como en otras oportunidades, el grupo padeció los efectos de la promulgación de la ley de prensa durante la presidencia de Perón, según la cual se distribuían arbitrariamente cuotas variables de papel a distintos editores. Asimismo, el ministro de Economía José Ber Gelbard interesado en extender sus vínculos políticos y comerciales al campo mediático (Seoane, 2009: 292)- generó las condiciones que llevarían a Civita a ceder su paquete accionario en Papel Prensa: se congelaron los financiamientos que el Estado se había comprometido a brindarle a la sociedad y que debían servir para pagar la maquinaria de la futura productora de papel (Gasparini, 2010: 35; Scarzanella, 2016: 220). Otro tipo de presiones políticas se hicieron sentir en agosto de 1973, cuando el establecimiento tipográfico de Abril en la localidad de Florida fue tomado por los trabajadores gráficos liderados por Raimundo Ongaro.

Ante esta coyuntura, el 27 de diciembre de 1973, Civita vendió su parte de Papel Prensa a Galería Da Vinci S. A., sociedad del banquero David Graiver, empresario vinculado al ministro Gelbard (Seoane, 2009: 290-293; Gasparini, 2010: 33-51). Inmediatamente después de la adquisición de Papel Prensa por parte de Graiver, un decreto declaró la producción de papel prioritaria para el desarrollo nacional y la sociedad fue favorecida con ingentes desgravaciones fiscales.

Luego de la muerte de Perón y el alejamiento de Gelbard del gobierno, la empresa se convirtió en un blanco de la AAA. El 28 de abril de 1975, la organización paramilitar hizo estallar una bomba lanza panfletos ante el edificio de la editorial, conteniendo amenazas a escritores, periodistas y a la familia Civita, la cual decidió abandonar el país (2) y dar por terminada la edición de Panorama. Los Civita se trasladaron primero a Brasil y luego a Montevideo y dejando la presidencia de la editorial en manos de Raúl Burzaco, quien se había desempeñado como director de dicha publicación desde 1972.

En marzo de 1976, Civita consideró que era posible volver a Argentina, ante la ausencia de Isabel Perón y José López Rega e intentó relanzar Panorama y retomar su actividad empresarial con normalidad. Pero descubrió que Abril se encontraba en la mira del almirante Emilio Massera y un nuevo ciclo de amenazas y atentados terminó en 1977 con la venta de la editorial a capitales ítalo-argentinos (3) y el exilio de los Civita en México. La revista, como el 
resto patrimonio de la editorial, terminó sucumbiendo ante las pujas políticas, la violencia y la corrupción propias de la tragedia argentina de la época.

\section{Panorama: entre el pluralismo político y el cálculo estratégico}

Panorama, la revista de nuestro tiempo apareció en junio de 1963 como una publicación mensual, fruto del acuerdo societario de Editorial Abril con Time-Life. Un par de años más tarde, Abril adquirió el porcentaje de Time y se constituyó la sociedad Panorama, con un capital de 2 millones. Su directorio estaba compuesto por Cesare Civita como presidente, acompañado por su hijo Carlo Civita, Alberto Levi y Emanuele Diena (Scarzanella, 2016: 151). Las revistas de actualidad que proliferaron en la época alentadas por el proceso de transformaciones socioculturales de entonces se inspiraban en el modelo de news magazine norteamericano y expresaban un nuevo periodismo, más interpretativo, en el cual confluían literatura e información (Taroncher, 2012: 29-45). En Panorama colaboraban muchos periodistas jóvenes en un clima de gran efervescencia, abordando una agenda que iba desde la actualidad política hasta la vida cotidiana. La dirección de la publicación (4) estimulaba el uso de encuestas y sondeos de opinión, así como el trabajo en equipo. En forma creciente, se plasmó la influencia del fotoperiodismo dentro del estilo adoptado por la revista y los editores fueron a un mayor protagonismo de los periodistas en el marco de entrevistas en tono más informal.

Su línea editorial paulatinamente iría definiendo un perfil antiperonista así como habría de sumarse a la campaña de desprestigio del presidente Arturo Illia (Carman, 2015: 502). Durante la dictadura instalada en 1966, Panorama apoyó el programa político del general Juan Carlos Onganía hasta que después del Cordobazo comenzó a tomar distancia crítica del gobierno militar, otorgando cada vez más espacio en su agenda a la cuestión del peronismo, la violencia y la conflictividad social.

En nuestro período de interés, 1973/1975, la revista tuvo una tirada promedio de más de 20.000 ejemplares semanales (5). En su staff periodístico (6) -definido por Ulanovsky como "hiperpolitizado" (1997: 228)- figuraban algunos colaboradores ligados a la izquierda revolucionaria -peronista y no peronista (7)-, pero las dos personalidades que se sucedieron en la dirección, Raúl Burzaco y Eduardo Maschwitz, poseían trayectorias políticas y socio profesionales que los vinculaban a las elites más conservadoras de aquel entonces (8).

Esa pluralidad de voces hizo de Panorama un medio singular y exitoso en términos comerciales. La revista estaba orientada a los sectores medios y altos de nuestra sociedad, a 
lectores que estuvieran ávidos de novedades de la actualidad nacional e internacional así como de innovaciones en materia de hábitos y consumos de distinción. Según sus propias palabras, este "nuevo tipo de lector" ya no exigía a la prensa gráfica noticias y rapidez -provistas por la radiofonía y la televisión- sino "explicaciones" (Panorama, 1973c: 27). Y el compromiso de Panorama con su público se proclamaba hacia su décimo aniversario en términos de "probidad informativa e intelectual, respeto por el lector, el tema tratado y las personas aludidas, rastreo constante de la actualidad y ubicación de ésta en el contexto que le permita interpretar el hecho..." (Panorama, 1973r: 3). En el concierto de publicaciones de la época, la revista se presentaba como "testigo e intérprete de la cambiante realidad" y anhelaba continuar con su tarea a fin de "perfeccionar el diálogo con el lector", propósito que consideraba como su "más profunda razón de ser" (Ídem).

Si bien en su línea editorial habría de apostar por el triunfo de Ricardo Balbín (UCRP) en las elecciones presidenciales de 1973 (Panorama, 1973e: 16-19, 34-35 y contratapa), luego de la victoria del peronismo adoptaría una posición contemporizadora y condescendiente hacia el nuevo gobierno y sus principales referentes. Como ya hemos mencionado, esta actitud no logró evitar las presiones político-económicas ni las agresiones hacia la empresa y sus propietarios por parte de sectores ligados a distintos funcionarios del Poder Ejecutivo. Desde el punto de vista del cálculo estratégico, la conducción de la revista decidió no utilizar la superficie redaccional como arena de combate en el conflicto con el gobierno que condujo a la venta de Papel Prensa al grupo Graiver en diciembre de 1973 ni posteriormente como espacio de denuncia del atentado que perpetró la Triple $A$ en el edificio de la editorial y que determinó la interrupción de la publicación en abril de 1975 y el primer exilio de los Civita. En términos de Héctor Borrat, la dirección de Panorama experimentó conflictos en su "propio cuerpo institucional" que decidió omitir de su temario (1989: 36), excluyendo la totalidad de los hechos que afectaron a la empresa y a su staff desde la asunción del presidente Cámpora hasta el abrupto cierre luego del Nro. 406, dando cuenta de las actuaciones del oficialismo en términos positivos y prescindiendo de los acontecimientos y las voces que pudieran reflejar el deterioro del gobierno y la gravedad de la interna peronista como una estrategia para lidiar con las críticas instancias que atravesaba la empresa y sus propietarios. A los fines de abordar el análisis del temario de Panorama, a continuación procederemos a exponer los aspectos más relevantes del discurso de la revista en relación al gobierno peronista y sus principales referentes desde las semanas finales de la campaña electoral del FREJULI hasta el cierre de la revista. 


\section{Panorama y el peronismo: una fallida apuesta a la prudencia}

La revista Panorama se estructuró entre 1973 y 1975 sobre una serie de secciones fijas entre las que se destacaban "La Argentina", "El Mundo" y "Off the record" por su extensa y meticulosa cobertura sobre la actualidad política nacional e internacional. La cuestión del retorno del peronismo al gobierno fue tratada en forma preferencial en la sección "La Argentina" así como en columnas y entrevistas a cargo de Jorge Lozano, Jorge Luis Bernetti, Ricardo Cámara y Armando Puente -este último desde Madrid-.

Aún antes de la asunción del gobierno del FREJULI, Panorama afirmaba que el peronismo triunfante ofrecía "otra integración política" en relación al momento de su derrocamiento en 1955 y su regreso al Poder Ejecutivo Nacional encerraba "un buen número de interrogantes" (1973f: 11), la mayor parte de ellos signados por las dificultades que le imponía la "lucha tendencial" (1973g: 11; 1973i: 12). Una vez convertido en oficialismo, la publicación comenzó a manifestar su entusiasmo por la "restauración justicialista" (1973l: 12), al sostener que el peronismo seguía siendo "la fuerza más sólida y progresista que admite el entourage del poder" (ídem), a pesar de las limitaciones que implicaba su "heterogeneidad" (1973o: 11). Luego de la renuncia de Héctor Cámpora el 13 de julio, la línea editorial habría de mostrar una moderada preocupación por la crisis que atravesaba al movimiento gobernante, causada, desde su óptica, por la convivencia en su seno de "proyectos contradictorios" que solo la conducción de Perón mantenía unificados (1973p: 4).

Precisamente, las representaciones en torno a la figura de Juan Domingo Perón -durante los primeros meses de 1973- pendulaban entre la imagen de la decrepitud y la vigencia del liderazgo de "caudillo justicialista" (1973a: 14; 1973k: 11). Por un lado, se lo muestra como "cansado de la política aldeana" (1973b: 13) y como paciente de la Dra. Aslan en Rumania especialista en geriatría- (1973d: 14). Pero por otro lado, se afirma categóricamente que Perón "a los 77 años, mantiene intactas ciertas condiciones de político excepcional" (1973e: 13); de "árbitro de la situación" en el marco de la interna peronista (1973f: 11). De hecho, los editores de Panorama despiertan en sus lectores grandes expectativas sobre las posibilidades de que Perón logre "la pulverización de las antinomias" dentro de su movimiento (1973: 12), mostrándolo "grave e irritado" en el marco de las reuniones que organizaba en Madrid para "frenar" a la tendencia revolucionaria y "zanjar la crisis que ponía en peligro sus esfuerzos para lograr una conciliación y unión de todos los argentinos" (1973i: 16). En esa misma nota, como el "Jefe del Movimiento Justicialista", se señalaba que a Perón "nadie lo maneja ni lo confunde" ya que su comportamiento era "el resultado de una reflexión personal, serena, madura, alejada de pasiones y simpatías, tomada con claridad y energía". Se lo presenta optando 
"tácticamente" por la "moderación" (1973j: 14), convertido en "el dirigente más lúcido que ofrece la clase dirigente argentina" (1973l: 12).

Luego de los hechos de Ezeiza y el discurso de Perón en relación a ellos, se afirmaba que en sus palabras se había expresado con "meridiana claridad" la necesidad de "unidad nacional", para lo cual se considera positivo su acercamiento al dirigente radical Ricardo Balbín (1973ñ: 3). Una vez definido el retorno del General a la presidencia, la revista celebró lo que se entendía como el fin del "pendulismo", al momento en que Perón había dispuesto la "depuración anti izquierdista en el movimiento mayoritario" en una "guerra declarada al marxismo" (1973t: tapa y 4). En vísperas de la asunción presidencial, se presentaba a un Perón "sagaz e inteligente" que había logrado hacer girar al justicialismo "hacia su viejo cauce ortodoxo" (1973t: 11), inaugurando una nueva etapa signada por la llegada del "centrismo al poder", una apuesta por el "orden" y la "alianza con los moderados de signo "nacional" (1973u: tapa y 4-5).

Por su parte, María Estela Martínez de Perón -“Isabel”- fue representada en términos altamente positivos al destacar su desempeño como "embajadora" del caudillo en su viaje a China, como la protagonista de "la gloriosa hora del Tercerismo" (1973j: 15; 1973k: 17) o bien como compañera de fórmula, por el hecho de constituir "la única figura inmune a la lucha de tendencias dentro del peronismo", cuya designación contribuyó a no agravar la "confrontación interna" (1973s: 5). A medida que la salud del Presidente fue mostrando signos de franco deterioro, Isabel comienza a tener más presencia en el temario de la revista, destacándose en términos altamente positivos sus alocuciones (1974b: 8), sus viajes por España y Suiza, así como sus entrevistas con personalidades destacadas (1974c: 16).

Ante la muerte de Perón, los editores de Panorama expresaron sus condolencias a la Presidente y pusieron de manifiesto su apoyo "ecuánime y desinteresado" al gobierno (1974d: 3). En esta etapa que atravesó entre julio de 1974 y su cierre a fines de abril de año siguiente, la publicación se lanzó a contribuir en forma entusiasta al proceso de construcción de la legitimidad del liderazgo de Isabel, señalando que, si bien carecía de "apoyaturas propias", la Presidente era "independiente de las corrientes que atraviesan el oficialismo" (1974e: 16), resaltando que estaba "dispuesta a gobernar". Se sostenía que la primera mandataria, pese a su "aparente fragilidad, atesora una energía que de ahora en más habrá que tener en cuenta", puesta de manifiesto en sus "advertencias" a gobernadores, senadores y diputados en relación quienes lleguen a cuestionar "la verticalidad" (1974f: tapa y p.1).

Se mostraba a la "Jefa del Estado" "lanzada a la conquista del poder" (1974f: tapa y p.12), haciendo una "demostración de fuerza" en Plaza de Mayo, exhibiendo "la firme decisión de mantener el liderazgo", saliendo "al cruce de los enemigos del gobierno, con argumentos 
simples pero contundentes" en materia de legislación laboral. (1974g: 11). En la cobertura de "EI 17 de Isabel", el cronista afirmaba que "ya nada ni nadie podrá discutir el liderazgo de Isabel Perón sobre el justicialismo", dado que luego de la gran manifestación de apoyo a la Presidente en la Plaza de Mayo del 17 de octubre, "no existe el peronismo sin Isabel, del mismo modo que antes del $1^{\circ}$ de julio, no existió el peronismo sin Perón". (1974h: 2). Se introdujo el término "isabelismo" en el discurso de la revista asociado a las figuras de la Presidente y de su ministro López Rega, al hacer especulaciones sobre los márgenes de maniobra con que contaba la jefa del Estado en el horizonte del advenimiento de 1975 (1975a: 10). Incluso en el período de descanso de "la señora Presidente" en la residencia de Chapadmalal, Panorama expuso su agitada agenda de trabajo y reuniones que la tenían como protagonista, entre las cuales se destacaban las vinculadas a la puesta en marcha del Operativo Independencia (1975b: 7, 11 y 14; 1975c: 7; 1975d: 8-9; 1975e: 8-9).

El rol de conductora de la Presidente sería resaltado también a partir de la cobertura de las elecciones de la provincia de Misiones, en las cuales los sectores de la izquierda peronista -ya abiertamente pasados a la oposición- recibieron una categórica derrota, hechos por los cuales la revista señalaba que había quedado en evidencia "la legitimidad política de Isabel Perón" como "algo indeleble" (1975f: 12-14).

De este modo, "la revalidación de Isabel como líder político" operaba como un fortalecimiento de la posición del ministro de Bienestar Social y secretario privado de la Presidente, José López Rega. Este personaje era representado como un funcionario exento de las polémicas que despertó dentro y fuera del gobierno. De hecho, Panorama llegó a destacar, en su penúltimo número, los elogios públicos que recibió de la primera mandataria "en un acto en el que Isabel quiso que estuvieran presentes todos los miembros del gabinete, el nuncio apostólico y los comandantes militares" (ídem). El "ministro" permanentemente era expuesto como vocero de los intereses de la esposa de Perón, tanto en sus viajes por el Tercer Mundo (1973j: 15; 1973/74: 14), como en la puja por acompañar al General en la fórmula presidencial (1973q: 4-5). En su esfuerzo por conquistar la buena voluntad de López Rega, la revista llegó de designarlo como "la segunda figura de la ortodoxia peronista" luego de Isabel y su socio en la ardua tarea de "mantener el principio de la verticalidad" dentro del convulsionado movimiento (1975a: 12).

En el amplio arco de posiciones que atravesó el gabinete presidencial desde 1973, este "secretario" era colocado "a la derecha de Juan Perón" junto a otro personaje de gran relevancia: el ministro de Economía José Ber Gelbard (1973o: 11), omitiendo la trama de intereses encontrados que se tendería entre ellos y terminaría con la salida de este último de su cartera luego de la muerte de Perón. En relación a la figura de Gelbard, Panorama extremó 
la sinuosidad de su discurso al oscilar entre la apuesta a las capacidades del ministro ante el "desafío económico" al que se enfrentaba con su Pacto Social (1973n: tapa; 1973p: 4) y las críticas moderadas a las proyecciones de sus resultados en relación su perfil "reformista" y regresivo en materia de distribución de la riqueza (1973n: 19).

En lo que respecta a este funcionario se destaca la omisión de cualquier referencia a la venta de Papel Prensa S.A. en la que Gelbard tuvo un desempeño determinante. En relación a esta empresa, entre enero y noviembre de 1973, es posible observar en el temario de la revista un recurrente interés por promocionar los intereses de los accionistas a los cuales estaba directamente vinculada al referir a distintos aspectos de la iniciativa en numerosas ediciones. Se abordaron los avances en la construcción de la planta en la localidad de San Pedro como manifestación del futuro abastecimiento nacional de papel para diarios y las expectativas que generaba el proyecto en materia laboral (1973f: 20; 1973m: 25; 1973o: 26; 1973p: 30; 1973v: 24). Pero en las semanas previas a la venta de la empresa al grupo de Graiver, la revista puso de manifiesto el reclamo del directorio de Papel Prensa S.A. para que desde el Estado se le imprimiera un nuevo impulso a la política del "autoabastecimiento" de papel para periódicos, obstaculizada por cuestiones burocráticas que demoraban las convocatorias internacionales en las cuales pretendían competir (1973m: 25). El proyecto de abastecer al mercado papelero local era presentada como "la solución nacional" para la crisis que atravesaba el sector a nivel global ya que pretendía "asegurar la total independencia de la Argentina respecto de los vaivenes mundiales", pero para ello era necesario el apoyo del Estado nacional, es decir, el acuerdo político del peronismo. Desde sus columnas, Panorama exhortaba al oficialismo a comprometerse en esta problemática al decir que "....ahora los plazos se acortan. Para poder cumplirlos son necesarias no sólo la energía y la audacia del sector empresario, sino también la decisión, diligencia y constancia de los funcionarios del gobierno" (1973p: 30).

La actitud adoptada por el gobierno peronista encarnada en la posición del ministro Gelbard daría por tierra con estas expectativas y Civita y sus socios accederían a la venta de la empresa papelera a un grupo con mejores contactos dentro del oficialismo. Ya en 1974, la revista pondría de manifiesto la nueva situación que atravesaba Abril al refugiarse en sus vínculos institucionales y emplear a la Asociación Argentina de Editores de Revistas (AAER) entidad en la cual César Civita era una personalidad gravitante desde sus orígenes en 1948como vocera de "las empresas periodísticas" para expresar con pesimismo las dificultades que sobrellevaba el sector debido a la escasez de papel prensa y sus altos precios internacionales, sin que el gobierno satisficiera sus demandas (1974a: 17).

De este modo, la revista expresaba el cálculo de riesgos que estaba haciendo su conducción. Ya se había perdido Papel Prensa, ahora estaba en peligro la propia existencia de la editorial 
ante la crisis a la economía en general. Por tal motivo, su dirección se esforzaba por interpelar al gobierno pero conservando el tono conciliador y realizando sus planteos con prudencia y un amplio respaldo institucional. Una tarea que resultaría infructuosa y no precisamente debido a la incompetencia de la conducción de Abril para ajustarse al contexto económico de la época sino por el rotundo fracaso en sus intentos por adaptarse a un entorno político en el que se vio rodeada de enemigos que la superaban en número y recursos.

\section{Consideraciones finales}

Hacia 1973, la revista Panorama se perfilaba como una consagrada cronista e intérprete de actualidad con una década de exitosa experiencia sobre sus hombros. Ante sus lectores, asumía el compromiso de narrar y comentar el beligerante devenir nacional que tenía como protagonistas a distintos actores de nuestro sistema político en tanto omitía deliberadamente de su temario aquellos conflictos en los que -de modo directo o indirecto- se veía involucrada como participante.

En la evaluación de los riesgos que corrían los intereses de la empresa a la que pertenecía y del capital periodístico y económico con el que contaba, la dirección de la revista decidió optar por la autocensura como una política editorial, ocultando ante los ojos de su audiencia las presiones, amenazas y atentados de los que era víctima por parte de sectores amparados por el oficialismo desde el Estado. Pero la operación de exclusión de información de sus columnas no se limitó a la cuestión del negocio del papel prensa o de las agresiones recibidas sino que incluyó hasta la más mínima referencia al creciente autoritarismo gubernamental e institucionalización de la violencia como herramienta represiva, el extendido recurso a la clausura de medios y la reducción de agencias de noticias, el vacío de poder que fue erosionando al gobierno desde la muerte de Perón, la lucha facciosa desatada en el peronismo bajo modalidades legales y clandestinas, la grave situación socioeconómica que atravesaba el país, entre otras.

En su intento por resolver satisfactoriamente los apremios que ponían en peligro su situación institucional como medio de comunicación pero sobre todo como voz pública de una empresa, Panorama orientó su discurso público y todas sus actuaciones en función de llegar a una instancia de entendimiento con sus contrincantes pero todos los esfuerzos fueron fútiles. La negociación parecía no entrar dentro de la agenda de sus adversarios, quienes comenzaron por desplazar al grupo Civita del negocio del papel hasta lograr borrar su impronta del propio mercado editorial. En una espiral indetenible, el recurso a la autocensura primero comprometió 
la ética profesional de Panorama en función de los intereses corporativos diversificados del holding que se veían asediados por oponentes de fuste. Luego, se puso a la revista al servicio de la mera supervivencia de Abril. Finalmente, bajo amenazas de muerte, se tomo la decisión de llamarse al silencio total, clausurando una experiencia que supo conocer tiempos felices de bonanza y prestigio y terminó subsumida en una angustiosa situación político-económica que habría de agravarse en el corto plazo para transformar el campo de los medios de comunicación y la vida cotidiana de los argentinos en profundidad.

\section{Notas}

(1) Hasta el momento, sólo hemos podido registrar un trabajo de investigación que toma a la revista Panorama como objeto de estudio. Nos referimos a la tesis de licenciatura en Ciencias de la Comunicación, Facultad de Ciencias Sociales de la UBA, de Gabriela Soledad García Ruano denominada "Panorama, la revista de nuestro tiempo. Una aproximación" (2016).

(2) Entre los amenazados se encontraban Alfredo Alcón, Sergio Renán, María Rosa Gallo, Luisina Brando, Leonor Manso, Roberto Cossa, Mario Benedetti, Ricardo Halac, David Stivel, Juan Carlos Gené, Tomás Eloy Martínez, Osvaldo Granados, Carlos Somigliana, César, Mina y Carlos Civita (cfr. Ulanovsky, 1997: 238).

(3) Se trataba del grupo Celulosa Rizzoli Empresas Asociadas (CREA), constituido por las sociedades Celulosa Argentina y Rizzoli. Celulosa Argentina llevó al grupo Editorial Julio Korn, pues había adquirido el 95\% de su paquete accionario en 1969. De este modo, las principales revistas argentinas pasaron a formar parte de un único gran grupo editorial, convirtiendo a CREA en el mayor grupo de América del Sur, con 22 títulos y una facturación de 3 millones de dólares mensuales (Ulanovsky, 1997: 213; Scarzanella, 2016: 231). Por su parte, la firma Rizzoli -de origen italianoestaba vinculada a la logia masónica Propaganda Due (P-2), liderada por Licio Gelli y de la que formaban parte destacadas personalidades del gobierno de facto como el propio Massera, por lo que CREA -junto a otras iniciativas mediáticas como II Corriere degli italiani en la Argentina, La Hora de Italia en Uruguay y II Giornale d'Italia en Brasilquedó bajo la órbita de la P-2 y sus aliados civiles y militares (Tognonato, 2013).

(4) Durante los años sesenta, Panorama fue dirigida por el yerno de Civita, Giorgio De Angeli (1963-1965) y luego por los periodistas Mario Bernaldo de Quirós (1965-1967) y Pedro Larralde (1967-1970) (cfr. Carman, 2015: 502-503).

(5) Fuente IVC. Hacia junio de 1968, la tirada se había vuelto semanal ante la necesidad de cubrir el candente acontecer político que vivía el país.

(6) Entre las figuras más renombradas del equipo de colaboradores de la revista entre 1973 y 1976 se destacan los periodistas Ricardo Cámara, Jorge Lozano, Jorge Luis Bernetti, Ana Basualdo y Fernando Lascano, los escritores y críticos culturales Ernesto Schoo, Rodolfo Rabanal y Marcelo Pichón Rivière, el antropólogo y crítico literario Miguel Ángel Bustos, la musicóloga Pola Suárez Urtubey, el periodista parlamentario Marcos Diskin, el escritor y crítico cinematográfico Néstor Tirri, los humoristas gráficos Lino Palacio (Flax), Joaquín Lavado (Quino) y Roberto Fontanarrosa, entre tantos otros.

(7) Citamos, a modo ilustrativo, los casos de Jorge Luis Bernetti y Miguel Ángel Bustos. Bernetti era yerno de Rodolfo Puiggrós -interventor en la UBA cercano a la izquierda peronista- e integrante de Montoneros. Fue Jefe de prensa de la gira electoral de Héctor Cámpora en 1973 (cfr. http://www.editorialoctubre.com.ar/team/jorge-luis-bernetti). Por su parte, Bustos era antropólogo, poeta, periodista y profesor en la UBA. Era militante del Partido Revolucionario de los Question, Vol. 1, N. 61, enero-marzo 2019. ISSN 1669-6581 
Trabajadores (PRT). Fue secuestrado por un grupo de tareas el 30 de mayo de 1976. Estuvo desaparecido desde entonces hasta 2014, cuando sus restos fueron identificados por el Equipo Argentino de Antropología Forense en una fosa común del cementerio de Avellaneda (cfr. http://www.desaparecidos.org/arg/victimas/b/bustosma/).

(8) Raúl Horacio Burzaco (1930-2004) fue periodista y profesor de Composición Literaria, Teatro y Literatura Hispanoamericana en el Instituto de Lenguas y Culturas (1958-63) y del Seminario de Investigación Periodística de la USAL (1984-96). Se desempeñó como Jefe de Internacionales y Prosecretario de Redacción en el diario La Prensa (PK) (1957-1962), como Director, Gerente Editorial, Gerente General y Presidente de la Editorial Abril y Director de las publicaciones Panorama, Siete Días y Corsa. Posteriormente, fue Director General de los diarios Tiempo Argentino (1982-1986) y El Cronista Comercial (1987-90). Fue vocero Presidencial de Carlos Menem (1991-94). Luego de la función pública ocupó la vicepresidencia del Multimedios América, fue presidente del Capítulo Argentino del Club de Roma y se desempeñó como consultor de la empresa Torneos y Competencias. Fue miembro de la Academia Nacional de Periodismo y distinguido con los Premios Reporte 1983, Cruz de Plata Esquiú 1984, Reporte 1987 y Premio Konex de Platino 1987, en el rubro Gráfica Periódica (cfr. http://www.fundacionkonex.org/b433-raul-horacio-burzaco y Ulanovsky, 1997: 305). Por su parte, Eduardo Maschwitz (1930-2010) fue abogado y periodista. Tataranieto del gral. Bartolomé Mitre, fundador del diario La Nación, al cual se incorporó en su juventud a la sección Deportes. Fue accionista y miembro del directorio de aquel periódico. Fue uno de los creadores de la revista Gente, de la cual fue jefe de redacción al igual que en la revista Siete Días. Fue, además, director del Boletín Oficial y presidente de la Fundación Ebbeke, vinculada al Colegio Labardén de San Isidro. Se destacó como rugbier del San Isidro Club (SIC), en el cual se desempeñaría como entrenador. En 1982, fue portavoz de Reynaldo Bignone, último presidente de facto de nuestro país (cfr. https://www.lanacion.com.ar/1322447-murio-eduardo-maschwitz).

\section{Bibliografía}

Águila, G.; Garano, S. y Scatizza, P. (Coords.). (2016). Represión estatal y violencia paraestatal en la historia reciente argentina: Nuevos abordajes a 40 años del golpe de Estado, La Plata: Universidad Nacional de La Plata.

Besoky, J. L. (2010). La revista El Caudillo de la Tercera Posición: órgano de expresión de la extrema derecha. Conflicto Social, 3(3), pp. 7-28.

Borrat, H. (1989). El periódico, actor político. Barcelona: Gili.

Borrelli, M. (2011a). Una "batalla ganada": Clarín y la compra de Papel Prensa (1976-1978). En Borrelli, M. y Saborido, J. (Comps.). Voces y silencios. La prensa argentina y la dictadura militar (1976-1983) (pp. 19-53). Buenos Aires: Eudeba.

Borrelli, M. (2011b). Criterio frente al golpe de Estado de 1976: una apuesta a la salida institucional. En Borrelli, M. y Saborido, J. (Comps.). Voces y silencios. La prensa argentina y la dictadura militar (1976-1983) (pp. 225-250). Buenos Aires: Eudeba.

Borrelli, M. (2015). En asedio permanente: la prensa argentina durante el gobierno de Isabel Perón (1974-1976). Punto Cero, 31, pp. 75-86. Recuperado de https://bit.ly/2GNwCvH 
Bufano, S. y Lotersztain, I. (Comps.) (2010). Evita Montonera. Revisión crítica de la revista oficial de Montoneros. Buenos Aires: Ejercitar la Memoria.

Carman, F. (2015). El poder de la palabra escrita: revistas y periódicos argentinos: 1955-1976. Buenos Aires: Biblioteca Nacional.

Cosse, I. (2013). Periodismo, género y estatus de lo cultural: nuevas formas de sociabilidad en La Argentina (1962-1969). Revista PerCursos, 14(27), pp. 221-241. Recuperado de https://bit.ly/2EYV1N4

Cucchetti, H. (2008). Redes sociales y retórica revolucionaria: una aproximación a la revista Las Bases (1971-1975). Nuevo Mundo Mundos Nuevos. Recuperado de https://journals.openedition.org/nuevomundo/43252

Díaz, C. L.; Giménez, M. y Passaro, M. (2001). La libertad de expresión entre dos fuegos 19741976. Oficios Terrestres. Facultad de Periodismo y Comunicación Social, VII(9/10), pp. 111-123.

Franco, M. (2012). Un enemigo para la nación. Buenos Aires: FCE.

Gasparini, J. (2010). Graiver, el banquero de los Montoneros. Buenos Aires: Norma.

Giordano, V. (2014). El erotismo en las imágenes de Adán, 1966-1968. Revista Caiana, 4. Recuperado de https://bit.ly/2GMTECG

Grassi, R. (2015). El descamisado. Periodismo sin aliento. Buenos Aires: Sudamericana.

Lida, C. E.; Crespo, H. y Yankelevich, P. (comps.) (2007). Argentina, 1976. Estudios en torno al golpe de estado. México: El Colegio de México, Centro de Estudios Históricos.

Manzano, V. (2017). La era de la juventud en Argentina. Cultura, política y sexualidad desde Perón hasta Videla. Buenos Aires: Fondo de Cultura Económica.

Nadra, G. y Nadra, Y. (2011). Montoneros: ideología y política en El descamisado. Buenos Aires: Corregidor.

Orbe, P. (2012a). 'Cruzada nacionalista' y periodismo: la revista 'Cabildo' ante el escenario mediático argentino (1973-1976). ALPHA, 35, pp. 41-66. Recuperado de https://scielo.conicyt.cl/pdf/alpha/n35/art_04.pdf

Orbe, P. (2012b). La 'salida militar' como única opción frente al comunismo: la experiencia chilena desde la mirada nacionalista católica argentina (1970-1974). Contemporánea: historia y problemas del siglo $X X, 3(3)$, pp. 115-131. Recuperado de https://bit.ly/2Sta4Se

Peller, M. (2007). Textos, imágenes y política. Sobre los modos de representación de la militancia armada en Estrella Roja del ERP. IV Jornadas de Historia de las Izquierdas. Prensa política, revistas culturales y emprendimientos editoriales de las izquierdas latinoamericanas, Buenos Aires, CeDInCl. 
Pozzoni, M. (2012). Una mirada sobre la militancia en los primeros años '70 a través de la revista Envido (1970-1973). Nuevos Mundo Mundos Nuevos. Recuperado de https://journals.openedition.org/nuevomundo/62672

Rodríguez, L. (2012). 'El "marxismo' y la universidad en la revista Mikael (1973-1984). Ciencia, Docencia y Tecnología, 45, pp. 147-162. Recuperado de http://www.redalyc.org/articulo.oa?id=14525317007

Rodríguez Agüero, E. (2007). Intelectuales y compromiso político en la Revista Crisis (Argentina, 1973-1976). IV Jornadas de Historia de las Izquierdas. Prensa política, revistas culturales y emprendimientos editoriales de las izquierdas latinoamericanas. Buenos Aires, CeDInCl.

Scarzanella, E. (2016). Abril. Un editor italiano en Buenos Aires, de Perón a Videla. Buenos Aires: Fondo de Cultura Económica.

Seoane, M. (2009). El burgués maldito. José Ber Gelbard, jefe de los empresarios nacionales, lobista político y ministro de Perón en los setenta. Buenos Aires: Debolsillo.

Slipak, D. (2015). Las revistas montoneras. Cómo la organización construyó su identidad a través de sus publicaciones. Buenos Aires: Siglo XXI.

Sonderéguer, M. (Sel.) (2008). Revista Crisis (1973-1976) Antología. Del intelectual comprometido al intelectual revolucionario. Buenos Aires: Universidad Nacional de Quilmes.

Taroncher, M. A. (2012). La caída de Illia. La trama oculta del poder mediático. Buenos Aires: Ediciones B.

Tognonato, C. (2013). Las tramas ocultas de Italia. En Verbitsky, H. y Bohoslavsky, J. P. (eds.). Cuentas pendientes. Los cómplices económicos de la dictadura (pp. 399-412). Buenos Aires: Siglo XXI editores.

Tortti, M. (2014). Auge y cierre de la movilización política en la lectura de las revistas Pasado y Presente y Envido durante 1973. VIII Jornadas de Sociología de la UNLP, La Plata, Buenos Aires. Recuperado de http://www.memoria.fahce.unlp.edu.ar/trab_eventos/ev.4327/ev.4327.pdf

Ulanovsky, C. (1997). Paren las rotativas. Historia de los grandes diarios, revistas y periodistas argentinos. Buenos Aires: Editora Espasa Calpe Argentina.

Vezzetti, H. (2013). Sobre la violencia revolucionaria. Memorias y olvidos. Buenos Aires: Siglo XXI editores. 


\section{Revistas consultadas}

Panorama (1973a). Perón ¿Quiere volver otra vez?, 297, pp. 14-15.

Panorama (1973b). La Argentina. El gobierno veranea y el tirano acecha, 298, pp. 12-13.

Panorama (1973c). Medios ¿Por qué baja la venta de los diarios?, 299, p. 27.

Panorama (1973d). Justicialismo. Gerovital H3 y el protocolo socialista, 303, p.14.

Panorama (1973e). La Argentina. 11 de marzo: El miedo a la verdad, pp. 12-13; La gran duda ¿por quién votar?, pp. 16-19; Un cambio radical, 306, pp. 34-35; Balbín Solución, contratapa. 306.

Panorama (1973f). La Argentina. Elecciones: Perón sabe y puede, pp. 12-13; Papel Prensa. La máquina que viene del frío, 307, p. 20.

Panorama (1973g). Nota de tapa. El difícil equilibrio, 309, p. 11.

Panorama (1973h). La Argentina. Al borde de las definiciones, 313, pp.12-13.

Panorama (1973i). Madrid: la sentencia de Juan Perón, 314, pp. 14-17.

Panorama (1973j). 25 de mayo de 1973: El nuevo amanecer peronista, 315, pp. 14-15.

Panorama (1973k). Nota de tapa. La Iglesia y el peronismo, 316, p. 11; Visitas. La hora gloriosa del tercerismo, p. 17.

Panorama (1973l). La Argentina. El gobierno de los argentinos, 317, pp. 12-13.

Panorama (1973m). Papel Prensa. La capital del papel para diarios, 319, p. 25.

Panorama (1973n). El desafío económico, 320, tapa y Producir, siempre producir, p. 19.

Panorama (1973ñ). Nota de tapa. El país que encontró Perón, 321, p. 3.

Panorama (1973o). El silencio de 40 días, p. 11; Papel prensa: Mercado mundial en crisis, 322, p. 26.

Panorama (1973p). La Argentina. Perón-Balbín (I): la hora de hamacarse, pp. 4-5; Papel prensa: la solución nacional, 323, p. 30.

Panorama (1973q). La Argentina. Vicepresidencia: La hora cero, 324, pp. 4-5.

Panorama (1973r). Nota del director, 325, p. 3.

Panorama (1973s). La Argentina. Perón-Isabel: La opción al poder (I), 326, pp. 4-5.

Panorama (1973t). La agenda de Perón. Gobernadores. Gabinete. Fuerzas Armadas. CGT. Universidad, tapa; La Argentina. Depuración: El péndulo se detuvo, pp. 4-5; De Onganía a Perón, 333, p. 11.

Panorama (1973u). El centrismo al poder, tapa.; La Argentina. ¿Un gabinete para cinco meses?", 334, pp. 4-5.

Panorama (1973v). Papel Prensa. De los planes a los hechos, 338, p. 24.

Panorama (1973/74). Viajeros. El misterio y las versiones, 345, p. 14. 
Panorama (1974a). Periodismo. La encrucijada del papel, 352, p. 17.

Panorama (1974b). La Argentina. Perón-Balbín: las consecuencias, 366, pp. 8-11.

Panorama (1974c). El viaje de Isabel Martínez, 367, p. 16.

Panorama (1974d). Carta del director, 369, p. 3.

Panorama (1974e). Mesas de trabajo: El poder de Isabel, 373, p. 16.

Panorama (1974f). Como se forja el liderazgo de Isabel, tapa; Nota de tapa, p. 1. Argentina. El liderazgo de Isabel, 375, p. 12.

Panorama (1974g). La Argentina. La decisión de Isabel, 378, pp. 11-14.

Panorama (1974h). Nota de tapa, 381, p. 2.

Panorama (1975a). La Argentina.1975: un año decisivo, 391, p. 10-12.

Panorama (1975b). Al lector, pp. 7; Gobierno: el descanso de Isabel, p. 11; Versiones. Sobre el mandato presidencial, 394, p.14.

Panorama (1975c). Al lector, 395, p. 7.

Panorama (1975d). La Argentina. Un proceso que ha terminado, 396, pp. 8-9.

Panorama (1975e). La Argentina. Ejército: El fin del repliegue militar, 397, pp. 8-9.

Panorama (1975f). Balance de una elección. Misiones: La legitimidad de Isabel, 405, pp. 12-14. 